EthnoAnthropoZoom

159.922.4:323.281(495.6:=163.3)

\author{
Biljana Bujko (USA) \\ Clinical Psychologist in Private Practice \\ e-mail: biljana.bujko@gmail.com
}

\title{
TRANSGENERATIONAL TRAUMA \& RESILIANCE: THE UNTHOUGHT KNOWN - NAMELESS RUPTURE AND REPAIR
}

\begin{abstract}
All forms of oppression, whether is racism, genocide, or exclusivity of a dominant group within a region or a country, is a system that impacts everyone within it, pervasively, deeply, and for the dominant group, often unconsciously. The transgenerational trauma is experience of violence perpetrated upon parents and transmitted to subsequent generations, a colonized mind of unbearable and unprocessed psychic experience without conscious knowledge and interest in being processed and transformed. The last 20 years research intensified on this topic, addressing the questions: How do we understand the vicissitudes of historical trauma? How do we help people create a vital connection to the "Other" given the shifts and splits still alive in today's culture? And most importantly, how do we understand and facilitate a relationship to a deeply felt, individual sense of self so that each may live a more authentic, meaningful life? The author describes what is trauma, how transgenerational transmission manifests, what are the causes, and how resilience develops. The final focus is on the psychology of the Macedonian ethnic identity, specifically reflecting on the Aegean Exodus and the wounds of the transgenerational trauma among this ethnic group.
\end{abstract}

Key words: trauma, transgenerational transmission, resilience, Macedonian identity, Aegean exile

The study of transgenerational transmission of trauma began with the research at Holocaust trauma. It has been in the past 20 years that scholarship on testimony, witnessing, and transgenerational transmission have extended beyond the Holocaust, to other political and social traumas and genocides. Large amount of research lately has been done on African-American slavery, Native-American invisibility in the US, Armenian and Cambodian genocides, and the Balkan war in the 1990's. 
Common large group traumas include wars, genocides, political persecution, and exile.

Why the notion exists in the human psyche that, in order for one person or group to feel better about themselves, there must be denigration of another? Violence against women and children is really violence against all humanity. All forms of oppression, whether is genocide, racism, or exclusivity of a dominant group within a country or a region, is a system that impacts everyone within it, pervasively, deeply, and for the dominant group, often unconsciously. The dominance of power of one group over another must be approached by education, dialogue and partnerships between men and women. Escape from violence requires a radical turn to the Other.

\section{Psychoanalytic perspectives on the theory of trauma}

For Freud, trauma in general is an experience of helplessness in the face of being overwhelmed. According to Freud, an individual is protected by a shield between the internal stimulus from the external stimulus. When that shield is broken or penetrated as a result of some shocking or unbearably painful event, flooding of unprocessed emotions occurs that causes overwhelming state of trauma.

Masud Khan (1963) a British psychoanalyst introduces the distinction between shock trauma v.s cumulative trauma. Shock trauma is immediate, sudden, a brush with death if you will. Examples of shock trauma are surviving a car crash, rape, or loss of a close person. On the other hand, process trauma or cumulative trauma is continuous trauma of pain and suffering: e.g. growing up with a dysfunctional or an alcoholic parent, living through a war, genocide, exile etc.

In the category of cumulative trauma, belongs the topic that we discuss today: historical trauma. What is historical trauma? Historical trauma has to do with collective cumulative emotional wounding over and across generations that results from massive cataclysmic events. These are events that don't just target individual, but target the whole collective community. The process that happens as a result causes personal trauma, but also it can be transmitted to later generations. Even the family members who did not have direct traumatic experience, can feel the effects of that event generations later. 
EthnoAnthropoZoom

\section{Concepts about trauma}

Understanding of basic concepts of trauma is needed first in order for one to understand the transgenerational transmission. The term trauma refers to an important interaction that has gone seriously wrong, when the caregiver, social system, or country fails to provide an attunement for painful feelings to a child or an adult. There are different kinds of trauma identified within the human experience. One well known and written about trauma is personal trauma that can happen for example as a result of a car accident, domestic violence, war experience and war trauma, which can cause PTSD. Personal means one person had the experience of that particular traumatic event or string of events, thus it is unique in its quality. In contrast, intergenerational trauma runs through generations, it is conscious and the transmission utilizes such processes as fantasy formation and identification. It is organized into a family narrative that is successively passed from one generation to the next. The stories told contain the information transmitted consciously to the next generation. On the other hand, transgenerational transmission of trauma refers to unconscious mental content, which is dissociated, primitive and un-integrated, further passed on subsequent generations in such unconscious form. This kind of transmission is not symbolized in words or through stories. In the essence of this kind of trauma are fragments or mental representations, pieces of told or untold story. They are usually expressed by acting out unprocessed emotions - such as hate or envy, engraved cultural beliefs, gestures, unnamed sadness, dread and anxiety, or recurring dreams and nightmares.

\section{Transgenerational trauma: causes and transmission}

The transgenerational trauma is most likely to be transmitted when large group trauma occurs. Here I want to explain the concept of "shared chosen trauma of a large group" that Volkan (2017) discussed extensively in his opus on trauma. When a large group like the Macedonian group, shares losses, feels helpless and victimized by another group and also share humiliating injury - this is key to identify the process of transgenerational transmission of past historical events (Volkan, 2002). One may ask why is then a "chosen" trauma, when the group does not choose to be victimized. It is chosen in fact, because just like an individual, a large group can be said to make unconscious "choices." Therefore, the term "chosen" reflects the unconscious choice. Although large groups may have sustained number of traumas throughout their his- 
tory, only some of them remain alive over a period of centuries. Thousands and millions of people in the large group share the mental representations of certain traumas. The chosen trauma then represents the incapacity of the prior traumatized generations to mourn their losses, as well as failing to reverse the humiliation, shame and injury to the group's self-esteem inflicted by another large group, usually geographical neighbor. This means that no matter what kind of trauma it is, it cannot be healed without a mourning process.

The mourning process, or the inability to mourn in immigrants, refugees, and other survivors of historical trauma, is the major cause for the transmission of transgenerational trauma. The situation becomes even more complex and tragic in cases of forced immigration (Volkan 2017). When people move from one location to a foreign one, they experience multiple profound losses: loss of family and friends, loss of home and country, loss of ancestors' burial grounds, loss of familiar language, food, smells, songs, loss of previous identity and its support system (Akhtar 1995). "All dislocation experiences can be examined in terms of the immigrant's or refugees ability to mourn and/or resist the mourning process." (Volkan 2017, 4)

Freud wrote his famous paper "Mourning and melancholia" in 1917 (Freud, 1917). He identified the process of mourning as experiencing the pain, and all other negative feelings about a loss. But, if a person had not gone through a mourning process after a traumatic experience, the melancholic state sets in and lasts for a long time. In many severely traumatized individuals, unresolved mourning may lead to a deficit in the ability to symbolize. These unmetabolized, unsymbolized mental structures are then transmitted to future generations. These fragments can be thought of as part of unconscious transgenerational transmission of hate, war and violence (Volkan 2017; Grand, \& Salberg 2017a; Grand, \& Salberg 2017b). Thus, the inability to mourn and be vulnerable to the psychic pain can cause the violence and trauma to continue to be passed on.

The mourning process is very complex, well represented and explained in the psychoanalytic literature. Here I will briefly mention a few basic distinctions of mourning, pertaining to the topic of transgenerational trauma. Grieving is an important part of the larger process of mourning, it is a transitory matter, a sublime expression of the pain. On the other hand, mourning is an entire process that takes time to resolve. Healthy mourning is expression of grieving and nostalgia, which is processing and letting go without prevailing feeling of hate. The people who are unable to mourn can be stuck in melancholia, which indicates the presence of feeling of hate and inability to mourn and let go. Another kind of fixation resulting from holding on to a specific object that reminds the person of the loss, or hearing the voices of the past related to the object of loss, is perennial mourning (Volkan 2017). 
EthnoAnthropoZoom

\section{How the transmission of TGT happens?}

I propose that the mode of transmission is much more understandable if we utilize the lens of attachment theories and research (Bowlby 1958, 1982). How a person carries within his or her mind and body numerous histories of experiences within the family's legacy of traumas and losses, along with the family's culture and external world? How do trauma survivors transmit these unspoken fragments to their children? This exploration I believe, is imperative for psychoanalysis.

Parents and children form an attachment unit that allows for deep unconscious communication of fear and safety, of anxiety and security, of closeness and distance, love and hatred, and so much more (Bowlby 1958). All of this is often transmitted through the registers of attunement and misattunement and the active process of self-other regulation of affects.

The French psychoanalyst Andre Green (1972) described a version of an absent parent experience for a child. He termed this kind of absent parent dead mother - someone alive, but not present; once alive, but now, due to depression turns into a blank or white state, absent from anxiety or mourning - psychosis blanche. The child detaches from this dead mother, while simultaneously identifying with her. In the unconscious psyche, the deadness and the loss of meaning are being installed.

Children are constantly observing their parents' gestures and affects, absorbing their parents' conscious and unconscious minds. In the shifting registers of attunement and misattunement, children adjust and adapt to the emotional presence and absence of their caregivers/ parents, always searching for attachment (Bowlby 1982). These searches begin at birth and occur before there are words, when there are gazes, stares, sounds, and touch - as well as the absence of these. This is how stories are told, even when not spoken, in the nonverbal and preverbal affective realms - silent and vocal, yet played out in subtexts, often on the implicit level. This begins to happen for a human being in the nucleus of the primal oedipal family, two parents and a child, which is a onegenerational model, and extends to a broader view that incorporates the influences of disrupted attachment across multiple generations (Grand, \& Salberg 2017a).

Fundamentally, attachment is the oxygen of our emotional lives, serving to create a feeling of safety and security, allowing us to be socially human and teaching us how to self-regulate our affective lives. When trauma revisits us transgenerationally, it is within the child empathic attunement and bond that the mode of transmissions can be found. When there is unmetabolized trauma on the part of the parent, the child in order to attach to the parent will need to enter and become enmeshed in 
the trauma scene. Both through empathic mirroring and dissociative attunement, the parents' trauma enters the child's cellular makeup before there are words, and thus before a narrative can be told. There is a haunting quality (Harris 2009) of the trangenerational transmissions, ghosts of trauma always linger where mourning has not occurred. To conclude, in the absence of a fully emotionally vital and present parent, the child attaches not only to what is available and present, but also to what is absent - what is alive as well as what is deadened. Empty circle, psychic holes, dead third, dying without dying are similar concepts that researchers had coined to describe the process of dissociation, fragmentation, and identification of a caregiver (Grand, \& Salberg, 2017a).

The psychoanalyst Vamik Volkan $(2002,2017)$ spent his entire career researching and writing about large group conflicts, the psychology of immigrants and refugees, and the transmission of transgenerational trauma. He proposed that the transgenerational trauma is passed on the child in two ways: by the unconscious processes of identification and depositing.

The identification process in early childhood happens when the child absorbs and internalizes the image of the parent, which I earlier explained with the attachment theory. However, there are other environmental influences the children integrate from their respective environments, which inform developing images of self and others, which are called mental representations (Volkan, 2002). The children identify with a range of aspects of significant individuals, from realistic ones to fantasized (e.g. heroes), wished for, or even evil ones. They assimilate mothering, fathering, sibling, and other mentoring functions. The identification process is also influenced by the larger group, to which the child's family belongs, like the church or society. These large groups communicate to the child religious, racial, and nationalistic messages, or messages of victimization and powerlessness. Early on the child learns to identify with the group through certain foods, dances, music, nursery rhymes, myths, folk stories, heroes, and important events.

Some of the hero figures that contribute to the sense of Macedonian identity are Krali Marko (King Marko), Alexander the Great, and Bolen Dojchin (Ailing Dojchin) (Bujko 2013). The two most popular Macedonian hero myths are "Болен Дојчин" (Ailing Dojchin) and "Крали Марко" (King Marko). The figure of Marko is depicted both as human, mortal and vulnerable, and as immortal and divine, attributed with nonhuman capacities. His character contained irreconcilable opposites. In “Болен Дојчин," Ailing Dojchin myth, the hero Dojchin is consumed by heavy illness; nontheless he finds power to combat the opressor, to save his sister's honor. Dojchin slays the Arab (the orpressor), but sadly dies at the end. This myth portrays the enormous strength of the Macedonian spirit that could transform the physically powereless people by the act of the hero, and could nurture the faith to be brave (Bujko 2013). In the 
same way, historical trauma can have way of shaping the child's identity, through the mental representations of the shared perceptions of the historical injury.

Depositing is another unconscious way of passing the transgenerational trauma. While the process of identification explains how the child assimilates aspects from his parents and environment into their self-image, depositing describes how the caregivers put their own historical traumatic experiences into the child (Volkan 2002). With the process of identification the child takes active role in selecting and integrating mental representations, but with depositing the child is a passive recipient of another person's history. Deposited representations in fact, illuminate how the transgenerational trauma is transmitted.

A common example of depositing of mental representations is the phenomenon of a replacement child. To illustrate what this means, I'll give an example. When parents lose a child to death, the mental image in their minds never dies. It persists to exist, and when a new child is born, this image is now given to the newborn and unconsciously becomes part of her or his self-image. The parent often relates to the second child as if it is the first one. Sometimes the new infant is given the name of the dead child, as well as the crib and the toys to play with. The newborn child has no experience of the dead one, it is in fact the parent who deposits the image of the dead child into the new child, and tasks the newborn to keep the dead child alive (Suistola and Volkan 2017).

Creating this dynamic of the replacement child is not unusual among the survivors of shared history trauma, such as war and persecution. In such cases, the image the survivor carries and deposits, is not of a dead child, but of the cumulative hurt endured, of a catastrophe, or shared trauma. The survivor, who had internalized self and object images linked with the injurious events, now unconsciously passes on, deposits or transmits these images onto their offsprings. These painful images are representations of wounded self -the victim within, and victimizing the other - the hate held toward the perpetrator, and all other painful emotions that come along with these mental representations.

What renders these situations traumatic and tragic, and helps continue to pass the trauma on, is the caregiver's inability to mourn the original tragic events and the losses. The unthought known, the term Bollas coined (1989), the internal knowing, is logged in the unconscious. Sometimes it is manifested as keeping secrets (melancholia), sometimes as holding onto objects or voices from the past (perennial mourning), and sometimes comes out in reoccurring dreams. 


\section{Is keeping secrets a manifestation of trangenerational trauma?}

Keeping secrets create the unthought knowns in the subsequent generations. Secrets can silently traumatize and cause the subsequent generation to feel the traumatic effect in different ways. There is no such thing as silence - meaning silence pertaining to keeping secrets. The passing of a secret from one generation to another can be delicate or obvious - and all of this can be silently transmitted. Once passed, they can even form life themes where they comprise a core of one's identity. Fonagy $(1998,2008)$, a contemporary psychoanalyst, insisted that there is an implicit "knowing" of the secrets of close others, which has to do with the process of mentalization (Fonagy \& Target 1998).

Mentalization is the individual's capacity to read another persons mind - in terms of intentions and emotions; and, in turn, the capacity to understand how one is read by another person or an audience. The mentalization usually occurs in a non-conscious or implicit fashion. For example, when a parent is unable to incorporate and think about a piece of reality, and cannot then enable the child to do so safely through playing with the frightening ideas, this reality Fonagy calls, psychic equivalence. Neither child nor parent can "metabolize" the thought and the "unthinkable" thoughts are passed from one generation to the next.

\section{How many generations can be affected from the TGT?}

The word "transgenerational" implies involvement of few generations in the process of transmission of trauma. Research shows that three or more generations can be caught up in the transmission, and sometimes up to seven. Faimberg (1988) coined the term telescoping of generations which means the parental past and child's current reality blur together, they become fuzzy as a result of the parental usage of the child - the depositing phenomenon. It may take half a century to process a war, and perhaps even longer gestational period of silence. 


\section{Epigenetics}

Epigenetics is a growing field which looks at the "bidirectional interchange between heredity and environment" or nurture v.s. nature. (Gotlieb 1999) It offers explanation of how environmental factors and historical time may affect gene expression and possible inheritable aspects of these expressions. For example, recent research in neuriscience suggests that epigenetics may account for some of the finings of transgenerational transmission of stress as measured from the research literature on rats. The link has been identified between disorganized attachment strategies and elevated Cortisol levels to stressors. In addition, human attachment studies have documented the inter-generational transmission of attachment strategies over three generations. Kohler (2012) in summarizing research findings about the effects of environment on epigenetics, writes:

Some epigenetic "marks," i.e., specific chemical attachments such as a methyl group, can be transgenerationally transmitted... In the context where epigenetics changes can be inherited and passed on to subsequent generations, the 'nurture' of one generation contributes to the 'nature' of subsequent generations.

In this way one must conceptualize transgenerational transmission in various and non-linear ways: transmissions are always multigenerational and utterly stimulated by context, both historical and personal, and are embedded in the mind and the body. No one theory can explain this exclusively, and for that reason one must draw from many sources, and consider various points of view to understand the complexity of the individual and group experience. For example, in my research on the Macedonian complex psyche, I explored the sociopolitical field, anthropology, history, and psychology (Bujko 2013).

\section{Resilience}

How can trauma be transmuted into positive experiences? What happens transgenerationally to diffuse or transmute what once was a horrific experience? Resilience in the psychoanalytic literature is defined as the capacity to metabolize the traumatic effects, the ability to overcome serious hardship. The literature barely begins to include an explicit look on the strengths transmitted to subsequent generations, 
and the enduring capacities for love, bonding, devotion, and activism that we often find in succeeding generations. To transmute violent repetitions into repair, these capacities need to be illuminated.

Attachment differs from trauma in that it is both broader and at the same time more explicit in its prediction of outcomes. Attachment happens in childhood only, trauma happens in adulthood too. This explains the factor of resilience. Resilience is individually defined based on the nature of attachment. If the child is securely attached and had good enough parenting, in the face of severe trauma resilience will be present.

There is also another component of role reversal that happens in relational trauma informing the development of resilience. The children of traumatized parents who are sometimes alive and sometimes deadened and dissociated, these children have no other way but to learn to attune to the parental states and attempting to regulate their affect and what's broken on the inside. This may also be the place in which the child grows a kind of resilience, since in role reversal the child is called upon to grow up sooner and to be, in a precocious manner, the one who manages feelings better. In psychology, the term parentification is used for these children. The transmission of strength, resourcefulness, and resilience operates in tandem with the transmission of wounds.

\section{The Macedonian Psyche}

How do we understand the Macedonian Psyche and what makes this group unique? I have been interested in studying the cosmogonic rituals of birth and dying and concluded through my research that not only they contributed to the formation of cultural, national and personal identity, but they are a symbolic form of expression of unconscious elements of both the TGT and the resilience.

As I have mentioned before, I have collected some narratives of group trauma and suffering through my research with informants, that is the oral tradition, but the large body of narratives in the Macedonian culture are passed through generations in the folk literature. Next, I will discuss and give example of chosen trauma among Macedonians.

The stories about the defeated heroes are fascinating in the Macedonian folk literature. In the Macedonian history Krali Marko was a father figure for the people, but rather a weakened father who lost power to make his people feel protected and secure. He was trapped between his desire to help his people, and his feeling of helplessness evoked by 
the real presence of the oppressor (Vražinovski 1999). This paradox is a theme of his tragic existence.

Similarly tragic existence had Bolen Dojcin, another defeated hero in the history. The national figure of Krali Marko represents the deepest psychological dynamic of the entire Macedonian group. His defeat against the giant force was tragic, but his loyalty and care represent the unbreakable group spirit of the people (Vražinovski 1999). These elements can be found in the Macedonian core identity.

\section{The Macedonian core identity (or complex)}

What is core identity? When a mental representation of massive collective trauma becomes an ethnic or national hallmark, a stamp, it must become weaved as part of the core identity of every individual of the large group: this is what chosen trauma means (Volkan 2017). Throughout the history, it is established that Macedonian people had struggled with finding recognition for their identity. In my previous research, I have worked on analyzing the complexity of the Macedonian Psyche (Bujko 2013). I have found that the Macedonian psyche contains a set of conscious and unconscious elements that form a particular complex. This complex is of bipolar nature, meaning, it contains both positive and negative behavioral patterns, previously transgenerationally integrated in the psyche. The fear of annihilation is the most fundamental fear and is a core element logged in the Macedonian psyche.

\section{Fear of annihilation and bipolarity of the complex}

As a result of many centuries of oppression and transgenerational trauma, the Macedonian group psyche became fragmented. In the absence of a strong paternal protective figure, Macedonians were exposed to essential positive masculine paternal aspects (Krali Marko who is the symbol for the name and identity), thus weakened and defeated mental representations were integrated in their group psyche, which led to development of a cultural complex or core identity. The dark shadow forces, some of them were the strength and power, were projected onto the "other," the oppressor - e.g. Crna Arapina (the Black Arab) or "Арапот" (The Arab) that represents the enemy of the people. Macedonians remained conscious of all the positive maternal aspects split off from the negative-weakened paternal ones. This explains the bipolar nature of the complex, and it gets triggered through the following process 
in the Macedonian psyche: The threat of recurring trauma and unsafe situations activates the defense, self-protective, self-care system, which sends further messages that if this group openly and aggressively expresses its dissatisfaction, might lead to group annihilation. The agitated fear of the aggressor, in the past the Ottoman oppressors, in present time Greece, arrests authentic expression; it seeks safe way to exist, and avoids to cause bad image or provoke anger in the world, that could trigger more oppression, exile, and annihilation, thus, it remains small and inferior. It destabilizes the self-esteem of the Macedonian group. Part of the fear of annihilation, is illustrated in the saying: "Macedonia will be non-existing, it will be divided again one day" (common saying), which exacerbate perpetual transgenerational threatening feeling of loss of identity and further transmits through generations.

\title{
Examples of TGT in the Macedonian Psyche:
}

Here is the account of Stana, a woman who was telling me a favorite bed-time story passed through generations in her family, carrying unconscious elements that gradually are becoming conscious through the narrative:

\begin{abstract}
"The old times, when the Turks were ruling, were very harsh times. The Romans were ruling first, three hundred years, then the Turks five hundred years, ... we, the Macedonians, are abused and maltreated. ... Since Aleksandar the Macedonian, we are cursed because of him ... because his mother wanted to poison him. The curse goes like this ... Macedonia should not exist, and the Macedonian name should not exist, ... the Macedonian people should be wretched and devastated, they should migrate to foreign lands, and not to remain in their own. This is why we are cursed, this is why Macedonian people move out in the world, they do not want to stay here." (Bujko 2013, 187)
\end{abstract}

Few themes in Stana's beliefs point to the importance of Macedonian identity. In the family of Alexander the Great, the ancient Macedonian, family betrayal precipitated a curse, which affected the future of Macedonia and the Macedonians. She attributed the current issues with the Greeks declining to recognize Macedonia to an ancient curse, coming from Alexander the Great, an ancient Macedonian hero whose young life ended tragically. This fear that Macedonia will not exist or will remain nameless is alive within Macedonian people's psyche. It lives actively in every person, as Stana's story demonstrates. However, through the transgenerational tension, Stana become resilient, trying to make the best out of her life (Bujko 2013). 
EthnoAnthropoZoom

\section{Examples of Resilience:}

The sorrow singers at the funerals in Macedonia, are common intermediary function to elicit grieving and mourning. Here is the account of one of my participants:

"They (the sorrow singers) lament both the dead and the living ... C'mon aunt, do not lament me, I am alive! When they begin ... they keep going on and on. If you do not tell them to stop, she will make you feel like you are dead. They cry for about an hour. Twenty women gather, and lament together for an hour, what a chaos! ... For example, if a young person dies, they go on sometimes for couple of hours, when we come home, we are swollen in our faces, grief stroken and crying." (Bujko 2013, 160)

What is the function of the sorrow singers: They are fostering the collective process of healthy mourning. The mourning then focuses not only on the dead person, but mourning of many other losses is being processed through the death of one person. And that facilitates the healing function, when the crying gates are open, the flood of memory of old losses is being grieved. If someone cannot tolerate that collective grief, or would avoid funerals altogether, that person is resisting mourning, that person may be stuck in the melancholic state and possibly carry the unconscious of TGT. That person is afraid of grieving because the pain may be too big, it may never stop, is the fear.

Macedonians knew well intuitively throughout centuries how to deal with the trauma. They had their rituals.

The birth and death rituals and beliefs not only provide the Macedonian people with religious, cultural, and cosmogonic meaning of human existence, but they provide a safe space for complex psychological healing, mainly involving identification, processing, and discharge of affect. The pagan elements in the rituals allow people to employ variety of symbolic representations, often products of the nature, to address the unspeakable, unconscious parts of the psyche, in which process much of the unprocessed affect becomes addressed and released. The sacred process of the rituals and the connection with the nature often induce somatic, cathartic, or visceral regulation of affect rather than only cognitive. The resiliency built over time is fostered by the safety of the rituals and people's beliefs about certain magical powers of the gifts from the nature.

The birth rituals are perinatal social transitions that provide cultural support for forty days postpartum. They have two functions a) wel- 
come the baby, b) help the mother to accustom to her new maternal role. They may reduce the onset of Postnatal Depression. The company of the women is crucial at this time as it normalizes, supports, and celebrates the experience for the new mother. Thus the mother is groomed to bond with her child, and foster secure attachment, which is the most important element for resilience.

The death rituals in Macedonia have two major functions: a) to enter the numinosity, a magical space where the living honor the dead and $b$ ) to elaborate process of mourning engaging the living, not only the closest family, but the wider community. The second function of the rituals engaging the living in the mourning process is invaluable for coming into acceptance and reanimating the living. The mourning process is complex and it seeks identification, expression, and validation of negative feelings. The participants then not only get in touch with their imminent feelings of loss, but much of their past trauma becomes processed to some degree as they witness the communal mourning, often involving the sorrow singers.

\section{Aegean Exodus and how to heal the wounds from the TGT}

During the Aegean Exodus, personal history was destroyed, subjectivity and peculiarity were erased, and human subjects became enumerated objects, nameless and unrecognizable. Their names were changed, they were forced to learn Greek language and forbidden to speak their own, by brutal methods employed by government officials. The people who were forced out of their homes and now in exile through Europe, US, Canada and Australia, still live with those "ghosts from the nursery" which are the ghosts from the past.

In the most recent history with the Aegean exodus, families were torn apart by separation, lost and alienated children were dispersed throughout the world. How do we ameliorate the helplessness, shame, humiliation, and victimization that these families endured? Many of the survivors of this tragic process gather to tell their stories in service of healing, but many carry within unconscious fragments of that trauma passing it onto the future generations. It remains both an individual and collective task of the Macedonian society to become more conscious of these elements because it is who we all are, this trauma is our core identity.

There are numerous ways how to help the unconscious to be illuminated and mourned. For example, within the close family system paying attention to the elderly's stories, listening to the narratives and mourning together may create intimacy and healing. Being attuned to 
the unconscious messages, the unspoken truths, secrets untold, visual expressions, as well as patterns that do not serve any longer may help elucidate traumatic feelings. Adults must be aware of how they speak to their children, and listen to the subliminal messages they pass on to them. Also, outside the family unit seeking communal support such as gathering with music, dance, celebrating birth, weddings, and mourning at funerals, helps bring people together into a collective emotional experience, especially because these are the cosmogonic rituals that foster mourning and resilience.

On a broader social level, engaging through peaceful activism for social justice provides personal gratification and valuable meaning making experience. For more severe or chronic presentations and problems, it is necessary to seek professional psychiatric and psychological help. In the community of mental-health professionals the focus should be on monitoring melancholic states, raising awareness of the necessity for help by organizing psycho-education on transgenerational trauma, probono work, or provision of proper referrals for psychotherapy and other social care services. It is extremely important for the families of survivor of transgenerational trauma to visit the old country, the sites where the trauma happened, as well as the monuments and the memorials to recall the events. Talking to people who witnessed the events, or those who can tell stories will help to learn the truth of what happened in the past. Learning the truth will help future generations to accept what happened in the past, mourn the pain, and re-integrate those experiences as a part of their identity.

\section{Prevention and professional help}

\section{The power of testimony and testimonial intervention}

During the process of testimonial intervention there must be an event and experience, sometimes long lasting, existing but unspoken and often not consciously formulated. This information then reaches the attention of a listener who is interested in receiving it, thus it becomes voiced out, recorded. Testimony is therefore a communication of information that satisfies the constant need to convey in the presence of an external readiness to receive. When the transmission of the story is complete, the survivor no longer feels alone under the pressure of the concealed secret, which prevents her to become prey to its tragic impact. The sense is now made of the internal sensations and affect, organized in a frame of a chronological narrative. By being voiced out, they are now remembered, passed on, and can be forgotten. The survi- 
vors of trauma must feel that there is a safe space and attention created for their story. It is deeply disappointing to them if they do not have an audience to witness their tragedy; they may easily close off, become depressed, and cocoon all the trauma inside, which will be then unconsciously transmitted.

This process can evolve successfully in therapy, however, if you are a child having capacity to listen to you parent, there is a third dimension opening for both, this is how the transgenerational effects are being recorded: the child must notice their affect about details of the story, to delineate what is their own remembrance of the story and what the reality of the story for the narrator is. Often it is difficult for children to imagine their parents needing to be children and be taken care for when the trauma was happening. Piecing together the gaps in the narrative is a way of reliving it together, which has a powerful effect.

\section{Psychotherapy}

One of the goals of psychoanalytic psychotherapy is to render conscious that which is unconscious, to extend the sphere of the ego, and to help patient become more aware of his past experiences of trauma, defining and differentiating his past and present reality, and understanding ways of relating with others. A clinical language and ethical frame are necessary to deal with the trauma and kind of relational curiosity that will foster the testimony. Cultural competence of a clinician alone does not open a dialogue. Clinician's knowledge of history and a careful review of the sociopolitical as well as the cultural history of a client's family in past generation is necessary to assess and treat transgenerational transmissions. Knowledge in history is necessary, to know what questions to ask - this is a key factor of competence.

Remembering, repeating, and working-through involved in the psychoanalytic pathway not only can restore emotional equilibrium, but also - by retracing the neuronal maps that link thoughts and emotions - may enable the biological damage to be reduced. Seeking an early professional treatment of transgenerational attachment trauma where the traumatized parent is offered a deeply empathic witness in a form of a therapist who could allow the parent/patient to gradually come out of dissociation and become able to experience pain, terror, and grief for the first time. In addition, the clinician could use Resilience Therapy, which is a kind of therapy that helps identify "ghosts in the nursery" - traumatic images, and finds "angels in the nursery", a protective factors that provide a source of internalized support and further foster resilience. Also, group process and group therapy often helps immigrants, refugees, and victims of trauma to feel supported, less isolated, and to foster a sense of belonging. 


\section{Conclusion}

When a person feels deceived consciously or unconsciously by the parent, leader, ideology, creed, or the deceptive partner, one feels so humiliated to have believed and needed to believe. The victim then carries, often suicidally, feelings of shame that should belong to the perpetrators. A shame always impedes, or at least complicates ones life, and needs remembering and mourning.

The psychological ability to know one's own identity is to consider historical facts, artifacts, myths and ways of being in the world, as well accepting the past and mourning the losses, which grants the authority to embrace one's own identity. This is fundamental factor in building the Macedonian self-confidence. Only then can this group negotiate their needs with the world, their presence, potential, and contribution.

Beyond deception and shame, each of us needs to engage the question of how the haunting past can be usefully remembered. To summarize, I would like to propose the following stance toward healing the wounds of the transgenerational trauma: telling the story to someone who can truly listen, mourning the past and the losses, building monuments and memorials, and gather for music, dance, and ritual. Consider that true memorials are turning in dialogue toward the Other.

\section{References}

Akhtar, S. 1995. “A Third Individuation: Immigration, Identity, And The Psychoanalytic Process", Journal of The American Psychoanalytic Association, 431051-1084.

Allen, J. G., Fonagy, P., \& Bateman, A. 2008. Mentalizing in Clinical Practice. Washington, DC: American Psychiatric Pub.

Allen, J. G., Fonagy, P., \& Bateman, A. 2008. Mentalizing in Clinical Practice. Washington, DC: American Psychiatric Pub. 
Bollas, C. 1989. The Shadow of the Object: Psychoanalysis of the Unthought Known. New York: Columbia Univ. Press.

Bowlby, J. 1958. "The nature of the child's tie to his mother", Int. J. Psycho-Anal. 39: 350-373.

Bowlby, J. 1982. Attachment. New York: Basic Books.

Bujko, B. 2013. Identifying Cultural Complex by Examining the Myth and Rituals About Birth and Dying in the Macedonian Culture and their Influence on Shaping the Ethnic/National Identity (Unpublished Doctoral Dissertation) Pacifica Graduate Institute, Carpinteria, CA.

Faimberg, H. 1988. “The telescoping of generations: Genealogy of certain identifications", Contemporary Psychoanalysis 24: 99-117.

Fonagy, P. \& Target, M. (1998). "Mentalization and the changing aims of child psychoanalysis”, Psychoanal. Dial. 8: 87-114.

Freud, S. 1917. Mourning and Melancholia. The Standard Edition of the Complete Psychological Works of Sigimund Freud, Volume XIV (19141916): On the History of the Psycho-Analytic Movement, Papers on Metapsychology and Other Works, 237-258.

Grand, S. \& Salberg, J. 2017a. Trans-Generational Trauma and the Other: Dialogue across history and difference. New York: Routledge.

Grand, S. \& Salberg, J. 2017b. Wounds of History: Repair and Resilience in the Trans-Generational Transmission of Trauma, New York: Routledge.

Green, A. 1972. The dead mother. In On Private Maddness, London: Rebus Press

Harris, A. 2009. You Must Remember This. Psychoanalytic Dialogues 19: 2-21. 
Khan, M.R. 1963. The Concept of Cumulative Trauma. Psychoanal. St. Child, 18: 286-306.

Kohler, B. 2012. Relational psychosis psychotherapy: a neuropsychoanalytic model. Paper presented at the meeting of the American Association of Psychoanalysis, Physicians, Washington, DC.

Ornstein, A. 2003. "Survival and Recovery: Psychoanalytic Reflections", Chapter 5, Progress in Self Psychology, 19: 85-105.

Suistola, J. \& Volkan, V. 2017. Religious Knives: Historical and Psychological Dimensions of Internantional Terrorism, Durham, NC: Pitchstone.

Volkan, V. 2017. Immigrants and Refugees: Trauma, Perennial Mourning, Prejudice, and Border Psychology. London: Karnac.

Volkan, V. 2002. The Third Reich in the Unconscious. New York: BrunnerRoutledge.

Vražinovski, T. 1999. Narodna tradicija: Religija, kultura. Skopje: Matica makedonska. 
EthnoAnthropoZoom 